\title{
El proceso erosivo y su incidencia
}

regional: Conservacionismo e

interacciones en la producción

de implementos agrícolas en

La Pampa (ca. 1940-1970)

The erossive process and it's incidence

in the region: Conservacionism and

interaction in the production of farm

implements in La Pampa (ca. 1940-1970)

\section{Federico Martocci}

Consejo Nacional de Investigaciones Científicas y Técnicas de Argentina (CONICET), Instituto de Estudios Históricos y Sociales de La Pampa (IEHSOLP) /

Universidad Nacional de La Pampa, Instituto de Estudios Socio-Históricos (IESH)

fedmartocci@hotmail.com 


\section{Resumen}

Para la historiografía ha pasado relativamente desapercibido un fenómeno que afectó a una amplia región del centro del país, en la que se incluía el oeste de Buenos Aires, el sur de Córdoba, una parte de San Luis y el este del Territorio Nacional de La Pampa. Se trató de una prolongada sequía que, entre las décadas del treinta y el cuarenta, afectó de modo disímil a esa extensa área de Argentina e impactó de manera negativa en la producción agropecuaria. Además, esto devino en un intenso proceso erosivo en La Pampa, que requirió la atención de autoridades locales y nacionales debido a que se trataba de un espacio cuya economía dependía de la producción primaria. En este artículo se analizará esa problemática entre los años cuarenta y sesenta, a partir del rol asumido por Industrias Maracó, una empresa pequeña que se convirtió en sinónimo de conservación del suelo y que, junto con técnicos estatales, produjo implementos esenciales para mejorar la explotación agrícola y prevenir la erosión eólica, especialización que se convirtió en la carta de presentación de la empresa a fines del período en estudio.

Palabras clave: erosión, prácticas agrícolas, conservación del suelo, Industrias Maracó

\section{Abstract}

To history, there is a phenomenon which has been unpercieved and has affected a wide region of the center of the country; including west of Buenos Aires, south of Córdoba, part of San Luis and east of National Territory of La Pampa. It was a lenghty draught in the decades of the thirties and the forties that affected, in different ways, to this wide area of Argentina and had a negative impact in agriculture. Furthermore, as a consequence, there was an intense erosive process that required the attention of local and national authorities because it was a region which it's main activity depended on primary activity. In this work this problematic is going to be analysed between the years fourty and sixty taking into account the role assumed by Maracó Industries, a small bussiness which became a symbol of soil conservation, and, in interaction with local technicians, produced essential implements that derived in the landmark of the bussiness by the end of the studied period.

Keywords: erosion, farm practices, soil conservation, Maracó Industries

Journal of Economic Literature (JEL): O30, N5, Q1, R10 


\section{Introducción}

En 1966, la empresa Industrias Maracó, fundada en 1937 y radicada en la ciudad de General Pico (al noreste de La Pampa), promocionaba sus implementos agrícolas en una revista e insertaba estas frases en la publicidad: "Cientos de médanos son monumentos para recordar errores pasados. [...] Trabajar bien la tierra no solo es buen negocio [,] es... un deber social. [...] Si Ud. quiere merecer el respeto de sus hijos déjeles un suelo fértil, no sus ruinas". 1 El planteo conservacionista, como intentaremos demostrar aquí, tenía un anclaje en la propia especialización de la empresa, pero no se puede desvincular del proceso erosivo que había afectado a una amplia región del centro de la Argentina desde la década del treinta. La sequía y los intensos vientos causaron no solo el descenso de la producción agropecuaria, sino también la degradación del suelo y, como consecuencia, la formación de extensas áreas medanosas. En este artículo exploramos el contexto económico regional que dio lugar a la especialización experimentada por Industrias Maracó desde fines de los años cuarenta e inicios de los cincuenta, con particular énfasis en las características de su producción y los vínculos que forjó con sectores profesionales orientados a la producción de saberes y prácticas aplicables a la producción en una región semiárida. Este análisis no se focaliza en la empresa mencionada como objeto de estudio, sino más bien es aporte que se propone, por un lado, explicar el despliegue de relaciones específicas entre actores privados y estatales con el fin de generar tecnología para el agro y, por otro lado, dar cuenta de la circulación transnacional de saberes en este proceso y del potencial que tenían esas innovaciones en un espacio afectado por la erosión eólica y la escasez de lluvias.

Si al promediar la década del sesenta esa empresa del norte de La Pampa apelaba a la conservación del suelo como estrategia para colocar sus productos, es elocuente que una parte considerable de los potenciales compradores estaban al menos familiarizados con esta problemática. Ahora bien, ¿cómo se relaciona ese planteo de Industrias Maracó con la crisis agroclimática precedente? ¿En qué medida los instrumentos agrícolas que allí se fabricaban contribuían a resolver los problemas más acuciantes que afrontaban los productores rurales? ¿Qué características presentaba la relación entre los integrantes de la firma y otros actores volcados al estudio de la erosión y la búsqueda de prácticas conservacionistas? Estas cuestiones

1 Zona Norte, n. ${ }^{\circ} 5,1966$, General Pico, s/n. 
que intentamos abordar no han recibido tratamiento por parte de la historiografía, a pesar de que permiten acercarse a una etapa compleja de la historia económica regional desde un punto de vista concreto: el rol del sector privado (que interactuaba con técnicos estatales) en la puesta a punto de tecnología específica para un espacio productivo semiárido, cuyas particularidades rebasaban claramente los límites administrativos. Esta perspectiva se complementa con otro estudio reciente que, si bien se centró en un período posterior, analizó con mayor detenimiento en la empresa el caso de Industrias Maracó como un ejemplo relevante para el desarrollo de la industria metalmecánica en La Pampa entre los años setenta y ochenta (Cantera, 2017). Asimismo, se apuesta a un enfoque diferente sobre un sector de la industria argentina que, como observó Claudio Belini (2017, pp. 316-328), experimentó un notorio avance (junto con la química y la petroquímica) entre mediados de la década del sesenta y comienzos de la siguiente, en detrimento de ramas más tradicionales. En provincias con una industria de maquinaria agrícola más arraigada y de mayor relevancia, los años desarrollistas fueron, por cierto, uno de los mejores momentos de su historia, tal como demostraron estudios específicos (Simonassi, 2013). La Pampa, que entre 1884 y 1951 fue Territorio Nacional, no alcanzó un desarrollo industrial significativo durante la segunda mitad del siglo $X X$, a pesar de que ese objetivo estuvo presente en las agendas oficiales entre fines de la década del cincuenta y toda la siguiente (Lluch, 2017). ${ }^{2}$

Pero este trabajo pretende aportar también en otro sentido. Por un lado, debido a que algunos estudios clásicos sobre la tecnología agropecuaria durante la segunda mitad del siglo XX se concentraron más en aspectos institucionales para explicar el papel del Instituto Nacional de Tecnología Agropecuaria (INTA) y desatendieron, en parte, todo lo que tiene que ver con las interacciones entre este último y otros actores vinculados con la producción agropecuaria. ${ }^{\mathbf{3}}$ Por otro lado, existen valiosas investigaciones centradas en la emergencia de tecnologías y prácticas conservacionistas sobre manejo del suelo en Argentina (Alapin, 2008); pero en ellas, las décadas centrales del siglo XX pierden relevancia analítica pese a que, como observaremos aquí, la temática de la erosión del suelo y de la necesidad de aplicar prácticas que favorezcan su conservación en una amplia zona del centro del país estaba presente en la agenda de las autoridades y en el discurso de los especialistas a cargo de su estudio. En este artículo proponemos explorar la vinculación entre actores privados y estatales orientados a la búsqueda de soluciones para enfrentar el proceso erosivo a partir de la noción de "marco tecnológico", que es lo suficientemente

2 En 1953, el Producto Bruto Geográfico (PBC) en La Pampa estaba compuesto en un 60,1\% por el sector primario; seguido por el terciario, con un $30,9 \%$, y por el secundario, con un $8,8 \%$. Para fines de esa década no se había modificado demasiado la distribución por sectores del PBC. Hacia 1970, el sector primario representaba aún el 55,89\% y el sector secundario el 12,48\% (Lluch y Comerci, 2011, p. 26).

3 Esto se observa, por ejemplo, en Ras (1994). 
amplia como para incluir los conceptos y las técnicas utilizados por determinados actores para la resolución de problemas específicos. En primer lugar, cabe señalar que esta noción comprende los conocimientos tácitos, las acciones sugeridas por sectores profesionales, los ensayos y las prácticas de uso de determinada tecnología. En segundo lugar, apunta a un abordaje constructivista de la tecnología, por lo tanto, no se hacen distinciones a priori entre los diferentes actores que intervienen y se privilegia el carácter interactivo de estos últimos. Para decirlo en los términos del autor de referencia, un marco tecnológico "es construido cuando comienza y continúa en el tiempo la interacción 'alrededor' de un artefacto" (Bijker, 2013, p. 81). De esta manera, este concepto puede usarse para explicar cómo el contexto estructura el diseño de un artefacto, así como también el modo en el que la tecnología incide en el contexto. Las personas que intervienen presentan diversos grados de inclusión en el marco tecnológico (grados que, a su vez, pueden variar con el tiempo), característica similar a la de los estudios que analizan este tipo de vínculos a partir de la categoría de "nodos", aplicada anteriormente por los historiadores argentinos para abordar las innovaciones en el agro pampeano entre fines del siglo XIX y comienzos del XX. ${ }^{4}$

A partir de un corpus documental conformado por informes técnicos, memorias de los gobernadores y del Ministerio de Agricultura de la Nación (MAN), publicaciones oficiales, textos destinados a la extensión rural, artículos de la prensa provincial y de las revistas de circulación regional, y estadísticas agropecuarias, sumado a testimonios orales de técnicos estatales y productores rurales, se pretende arrojar mayor claridad sobre la incidencia de Industrias Maracó en la tecnificación del agro pampeano con un criterio conservacionista. De este modo, es posible volver sobre trabajos clásicos que abordaron estas temáticas para, en primer lugar, complejizar la mirada en cuanto a la historia de la conservación del suelo y su vinculación con la industria de maquinaria agrícola y, en segundo lugar, retomar el argumento sobre la capacidad del sector para adaptar innovaciones generadas en otros países. ${ }^{\mathbf{5}}$ A continuación, se aborda cómo el proceso erosivo se convirtió en un problema para las autoridades y los especialistas que estaban a cargo de su estudio entre los años cuarenta y cincuenta. Luego, se exploran los inicios de Industrias Maracó, en un marco signado por la crisis agroclimática, y su orientación hacia la producción de herramientas agrícolas desde comienzos de la década del cincuenta. Finalmente, nos detenemos en las interacciones (especialmente, entre integrantes de esta firma y técnicos del INTA) y la circulación de conocimientos (por ejemplo, los que provenían de Estados Unidos) que tuvieron lugar durante la puesta a punto de maquinaria adecuada para trabajar el suelo en la región semiárida.

4 Véase Djenderedjian, Bearzotti y Martirén (2010) y Martocci (2014).

5 En este sentido, referimos especialmente al aporte de Huici (1988). 


\section{La erosión como problema}

La erosión eólica del suelo era un problema que ya había azotado duramente al Territorio Nacional de La Pampa (TNLP) ${ }^{6}$ durante la década del treinta, de manera contemporánea a lo sucedido en Estados Unidos a causa de las sequías que afectaron a las Ilanuras y praderas desde el Colfo de México hasta Canadá entre 1932 y 1939. El fenómeno, conocido como DustBowl, afectó el oeste de Kansas, el sudeste de Colorado, parte de Oklahoma, el norte de Texas y el noreste de Nuevo México. Entre las consecuencias más graves se destaca la erosión provocada por el accionar del viento, según se puede observar en una obra ya clásica al respecto (Worster, 1979). ${ }^{7}$ La problemática fue abordada rápidamente por el Gobierno norteamericano: en 1933 se estableció el Servicio de Erosión del Suelo, reemplazado en 1935 por el Servicio de Conservación del Suelo (SCS), cuya actividad se enfocó en el relevamiento de las zonas afectadas y la búsqueda de alternativas para resolver el problema. En 1934 se publicó un detallado reconocimiento del proceso erosivo y, en 1936, el SCS difundió un mapa con las áreas afectadas (en diferentes magnitudes), que fue ampliado con mayores detalles en 1937 (Hornbeck, 2009, pp. 9-10). ${ }^{8}$ Desde luego, no todos los agricultores de ese país estuvieron en condiciones similares para adoptar las técnicas recomendadas por el SCS, ya que los más pequeños tenían menos posibilidades de invertir capital en el control de la erosión (Hansen y Libecap, 2004). En cuanto a la Argentina, el proceso erosivo tuvo ciertas particularidades y no se vincula directamente con lo ocurrido en Estados Unidos; de hecho, algunas de sus características fueron advertidas por especialistas en Agronomía y Botánica, quienes Ilamaron la atención entonces sobre la situación pampeana (Di Liscia y Martocci, 2012), y luego se hicieron estudios más detallados, como analizaremos en estas páginas.

En esa coyuntura, las autoridades del TNLP Ilamaban la atención del Cobierno nacional y en sus memorias desarrollaban estas cuestiones. El gobernador Evaristo Pérez Virasoro, quien permaneció en ese cargo entre 1933 y 1939, planteaba en una de ellas que, durante 1937, la actividad agrícola y ganadera, "dos fuentes principales de la riqueza del Territorio", habían sufrido un "rudo golpe". Según explicaba el mandatario, la región había sido "azotada por fuertes e insistentes vientos, que convirtieron lo que en otros años fueron fértiles tierras, espléndidos alfalfares y prados naturales destinados a pastar hacienda, en enormes extensiones de médanos". La historia de la producción agropecuaria en esta zona, añadía, no registraba "una

6 La actual provincia de La Pampa fue, entre 1884-1951, Territorio Nacional de La Pampa, denominación que conservó hasta su provincialización en 1951, momento a partir del que se llamó provincia Eva Perón. Sin embargo, luego de la autodenominada Revolución Libertadora, volvió a tener el nombre de La Pampa, que conserva hasta ahora.

7 Para ampliar, véase Schubert, Suarez, Pegion, Koster y Bacmeister (2004).

8 En lo que refiere a las acciones oficiales, se pueden encontrar mayores detalles en Worster (1979) y Cunfer (2005). 
situación igual o parecida", con el agravante de que, entonces, la sequía era tan general que afectaba el centro y norte del TNLP, y también las provincias limítrofes de San Luis, Córdoba y Buenos Aires (Pérez Virasoro, 1938, p. 63). Ese año fue particularmente difícil para el sector rural, pero en realidad la sequía venía afectando notablemente el desarrollo de la agricultura pampeana desde fines de la década de 1920. Esta situación se evidencia a partir del descenso del área sembrada con trigo, lino y maíz (que ocupaban, respectivamente, la mayor parte de las tierras de cultivo), a la vez que se incrementaba la superficie cultivada con pasturas (por ejemplo, el centeno). Esto se observa con claridad en el siguiente cuadro.

\section{Cuadro 1. Hectáreas sembradas con trigo, lino, maíz y centeno (1928-1940)}

\begin{tabular}{|c|c|c|c|c|}
\hline Años & Trigo (ha) & Lino (ha) & Maíz (ha) & Centeno (ha) \\
\hline $1928-29$ & 1.149 .000 & 82.500 & 189.300 & 167.900 \\
\hline $1929-30$ & 956.800 & 52.000 & 194.200 & 193.200 \\
\hline $1930-31$ & 918.000 & 39.700 & 350.000 & 164.400 \\
\hline $1931-32$ & 597.200 & 27.300 & 334.000 & 180.000 \\
\hline $1932-33$ & 519.000 & 20.750 & 290.000 & 247.000 \\
\hline $1933-34$ & 739.000 & 13.290 & 279.000 & 293.500 \\
\hline $1934-35$ & 674.900 & 21.610 & 302.000 & 393.200 \\
\hline $1935-36$ & 512.000 & 19.000 & 327.000 & 335.000 \\
\hline $1936-37$ & 518.870 & 9.280 & 180.000 & 421.850 \\
\hline $1937-38$ & 600.000 & 4.500 & 182.595 & 445.600 \\
\hline $1938-39$ & 602.500 & 6.150 & 62.000 & 414.000 \\
\hline $1939-40$ & 505.000 & 450 & 208.000 & 365.000 \\
\hline
\end{tabular}

Fuente: elaboración propia a partir de Duval (1941, p. 152).

Desde ese momento, la necesidad de incrementar la cantidad de dependencias del MAN en el TNLP (en especial, de estaciones experimentales y agronomías regionales), así como el reclamo para instalar una escuela de Agricultura en la zona, se tornó una constante en los gobernadores locales. A partir de la Memoria de Pérez Virasoro, y hasta la que presentó el mandatario peronista Juan Páez(1948) a fines de los años cuarenta, esas peticiones se incluyeron en la agenda del Cobierno. Para justificar, en parte, sus planteos, Miguel Duval (que ocupó el cargo de gobernador del TNLP entre 1939 y 1946) exponía abundante información cuantitativa en la que destacaba cuál era la situación de la producción agropecuaria. Por citar un ejemplo, se puede observar la caída de la producción de trigo, que hasta fines de la década del veinte había tenido una gran relevancia y que conservaría cierta importancia en la siguiente, pese a la pérdida de significación ante al avance de los cultivos destinados a forraje. En la campaña 1928-29 se produjeron 773.800 t de trigo en el TNLP, 
guarismo que cayó a 187.920 t en la de 1929-30, que fue muy mala por la sequía reinante, y luego se recuperó progresivamente hasta alcanzar las 562.323 t en 1934-35. Desde ese momento, volvió a caer de manera notable en algunos años: 115.000 t en 1935-36, 101.897 t en 1937-38 y 315.200 t en 1939-40 (Duval, 1941, p. 161).

Al mismo tiempo, el gobernador Duval (1940, p. 17) advertía los efectos perjudiciales del viento, que arrebataba la escasa humedad del suelo y provocaba "el fenómeno de la erosión" en las tierras de labranza, problema que -afirmaba- "tanto ha preocupado en los últimos tiempos al Cobierno Federal". Probablemente influido por las opiniones de los técnicos del MAN, el mandatario cuestionaba el cultivo extensivo y el monocultivo de trigo, que constituían -según él- los "mayores riesgos" de la agricultura pampeana y en gran medida eran el fruto de la "improvisación" de los propios productores, quienes no aprovechaban los beneficios de la explotación mixta y, a veces, no aplicaban métodos "racionales" de cultivo (Duval, 1940, pp. 26-33). En efecto, como afirmaba Duval, entre fines de los años treinta e inicios de los cuarenta, la sequía y la erosión se convirtieron en verdaderos problemas para el Gobierno nacional, situación que se refleja en las medidas tomadas por el MAN. Según los textos oficiales de entonces, se designó una comisión para que estudiara y propusiera medidas con el fin de trasladar a los colonos de las zonas afectadas por la erosión del suelo que, según afirmaban, afectaba los campos del TNLP, el oeste bonaerense, el sur de Córdoba, San Luis y Santiago del Estero. Estas zonas habían sido clasificadas como "marginales" para el cultivo de trigo de acuerdo a la opinión de los especialistas, razón por la que sugerían reorientar las explotaciones y, en especial, fomentar la crianza de ganado y el cultivo de forrajes. Planteaban claramente que la erosión se debía a los "factores climáticos adversos" y la "remoción de las tierras por el arado" (en referencia al arado de rejas). ${ }^{9}$

Las tareas orientadas al "estudio sistemático del suelo del país" comenzaron en los años treinta en el marco del Laboratorio de Química de la Dirección de Agricultura, aunque con escaso personal técnico y recursos materiales, lo que "no permitió encarar ese problema integralmente y en toda su importancia". A fines de esa década, en 1938, se creó la División de Suelos en el MAN, que contaba con un laboratorio dividido en las secciones Análisis Mecánico, Análisis Químico, Física y Agrotecnia, Físico-Química y Fertilidad. ${ }^{10}$ En 1940, el MAN convocó a una reunión de "técnicos" para tratar "los problemas de la erosión", en la que se sugería que el Estado estuviera facultado (mediante una legislación específica) "para prohibir todas aquellas prácticas agrarias que traigan como consecuencia la destrucción de las condiciones de fertilidad del suelo". Además, sugirieron la creación de estaciones experimentales destinadas al estudio de la erosión y la búsqueda de forrajeras adecuadas para

9 Ministerio de Agricultura de la Nación (1940a, pp. 257-258).

10 Ministerio de Agricultura de la Nación (1940b, p. 76). 
suelos erosionables, entre otras iniciativas. ${ }^{11}$ También, por intermedio del MAN, se organizaron comisiones de técnicos para estudiar la problemática en dos zonas: San Luis y el suroeste de Córdoba, por un lado, y el centro, el norte y el sur del TNLP, por otro. En esta última, que comprendía aproximadamente 1.500 .000 hectáreas, se sugería adoptar sistemas de cultivo especiales (como el Lister, en líneas espaciadas), respetar las épocas de siembra, implementar la chacra mixta, hacer rotación de cultivos, evitar la roturación del suelo entre junio y septiembre (debido a que son meses ventosos), y realizar "una reja liviana" en el suelo luego de levantada la cosecha a fin de incorporar materia orgánica y conservar la humedad. En un área puntual de la zona sur del TNLP, incluso planteaban la necesidad de abandonar el cultivo de cereales y oleaginosas, a los efectos de orientar las tierras a la producción de forraje con destino a pastoreo. ${ }^{\mathbf{1 2}}$

\section{Imagen 1. Región semiárida sur (sombreado en el mapa)}

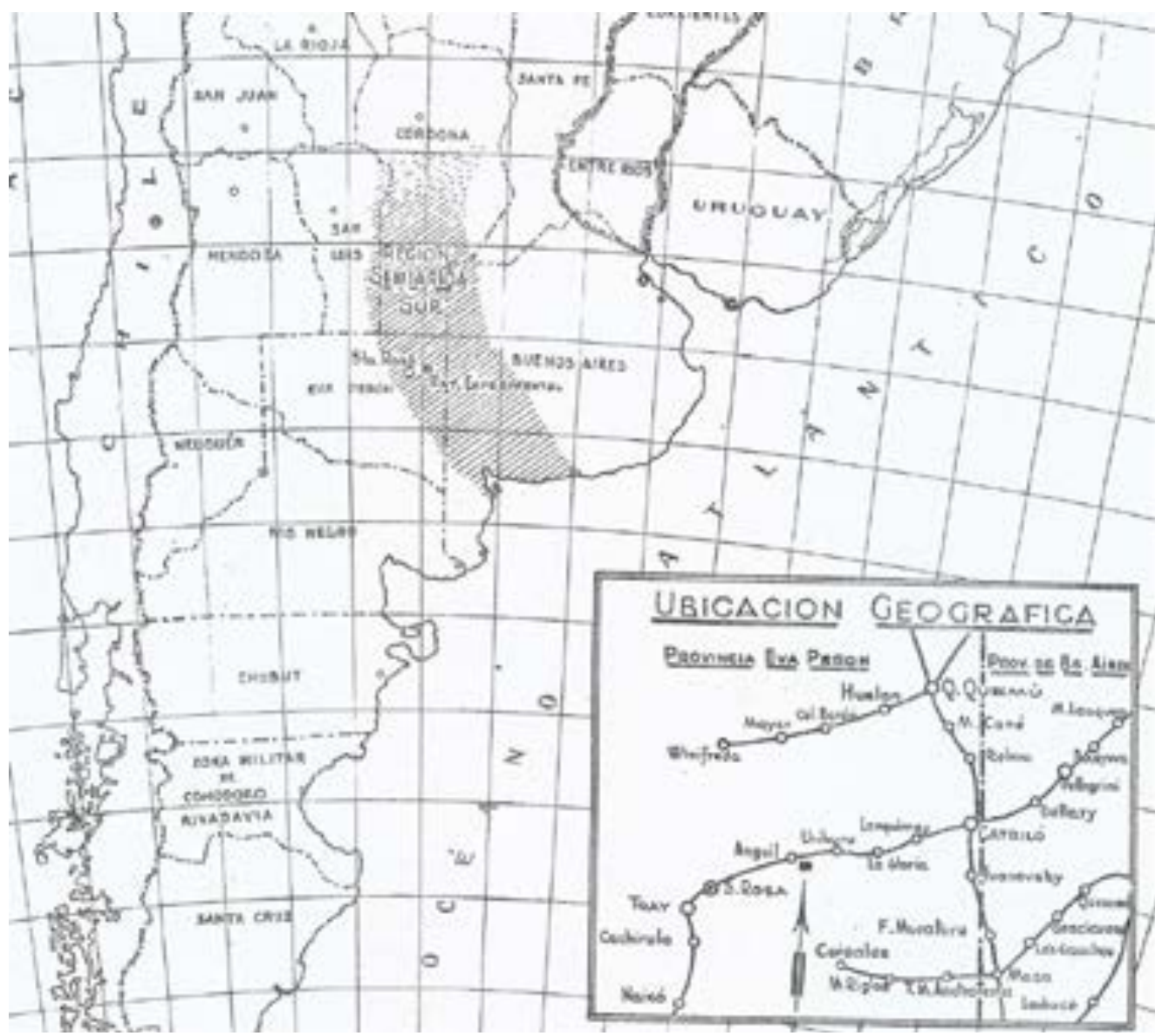

Fuente: Prego, Tallarico, Bellón y Calcagno (1955, s/n).

11 Ministerio de Agricultura de la Nación (1941, pp. 263-269)

12 Ministerio de Agricultura de la Nación (1941, pp. 269-273). 
Como es posible advertir, diversas acciones habían sido emprendidas por el MAN entre las postrimerías de los años treinta e inicios de los cuarenta, pero no se había avanzado aún en el relevamiento y los estudios de la erosión en la región central del país, más adelante denominada región semiárida sur, que puede observarse en el mapa.

Sin embargo, la problemática no perdió vigencia y, según relata un referente en el tema, en 1944 comenzó a funcionar el Instituto de Suelos y Agrotecnia (ISyA), cuya base organizativa provenía de la mencionada División de Suelos y continuaría trabajando en la elaboración de un inventario del proceso erosivo que afectaba a un extenso espacio del centro de la Argentina (Ipucha Aguerre, 1964, pp. 5-6). La conservación del suelo tuvo especial importancia para el ISyA y, luego de un intenso período de sequías que se extendió desde 1949 hasta los albores de la década siguiente, algunos de sus técnicos participaron en un simposio acerca del descenso de la fertilidad del suelo en esa región auspiciado por la Sociedad Argentina de Agronomía. Los diferentes aportes, posteriormente, se difundieron como una publicación del ISyA. ${ }^{\mathbf{1 3}} \mathrm{A}$ partir de la creación del INTA, tanto la masa crítica como los especialistas del ISyA pasaron a depender de esa Institución (Ipucha Aguerre, 1964, p.7). La problemática, a su vez, adquirió carácter internacional: en 1951, la Unesco comenzó a trabajar orgánicamente para mejorar el conocimiento sobre las tierras áridas. De acuerdo a uno de los técnicos más importantes del ISyA, en 1958 el tema alcanzó estado público en la Argentina, por lo que se creó el Comité de Estudio de las Regiones Áridas y Semiáridas y, a mediados de 1960, se llevó a cabo en Santa Rosa (La Pampa) la Primera Reunión de Defensa contra la Sequía y la Erosión en la Región Pampeana Semiárida. Dos años después, se realizó en Mendoza la Primera Reunión Nacional para el Estudio de los Problemas de las Regiones Áridas y Semiáridas, organizada por el mismo Comité. En esta Reunión se aprobó el Estatuto del Comité Argentino para el Estudio de las Regiones Áridas y Semiáridas y se eligió la primera Junta Directiva, cuyo presidente fue el ingeniero agrónomo Alberto Soriano, un destacado profesor de la Facultad de Agronomía de la UBA (Prego, 1967, pp. 6-7). ${ }^{\mathbf{1 4}}$

Como se puede advertir, entre los años cuarenta y comienzos de los cincuenta el proceso erosivo alcanzó un lugar destacado en las agendas de las autoridades argentinas, situación que derivó en la organización de dependencias específicas y la realización de los primeros relevamientos y estudios por los técnicos del MAN. No obstante, no todas las iniciativas pudieron concretarse y algunas se demoraron mucho tiempo, a diferencia de lo ocurrido en el caso de Estados Unidos, donde la erosión llevó al Cobierno a tomar medidas que arrojaron resultados concretos en los años treinta. Por ejemplo, en lo que respecta a La Pampa, a pesar de que ya a inicios de la década del cuarenta los técnicos recomendaron instalar estaciones ex-

13 Véase Molfino, Prego, Offermann, Zaffanella y Reichart (1952).

14 Para ampliar, ver Ipucha Aguerre (1966). 
perimentales para estudiar el proceso erosivo y buscar prácticas aplicables a las zonas erosionadas, la Estación Experimental Agropecuaria (EEA) de Anguil se fundó recién en $1954 .{ }^{15}$ Para su creación, cabe señalar, fue importante el estudio previo que llevaron a cabo los técnicos del ISyA, en el que plantearon con claridad las experiencias que debían desarrollarse en la Institución para atender los problemas vigentes. Entre ellas, se destacaban las prácticas de laboreo del suelo con diversos tipos de arados, el sistema Lister y el empleo de varillas escardadoras, el cultivo en contorno (poceado con discos excéntricos, líneas de nivel y terrazas de absorción), la realización de barbechos, evaluaciones de la densidad de los cultivos y ensayos para captar el agua de lluvia, por citar algunas. A su vez, preveían la adaptación y el mejoramiento de ciertas especies forrajeras y la implantación de pasturas, con el objetivo de proteger el suelo y orientar de manera gradual la agricultura cerealera hacia una función complementaria de la actividad ganadera (Prego, Tallarico, Bellón y Calcagno, 1955, pp. 12-15). Desde su creación, la EEA estuvo vinculada con diversos actores productivos de la región, y la empresa Industrias Maracó, como veremos en los siguientes apartados, tuvo un rol clave en ese sentido. Al demostrar esta interacción, no solo pretendemos explicar la sinergia entre actores estatales y privados, sino también la emergencia de tecnología que fue vital en las décadas analizadas debido a su carácter conservacionista y a la utilidad que tenía en una amplia zona fuertemente afectada por la erosión.

\section{Industrias Maracó: una empresa surgida en el marco de la crisis}

La empresa había sido fundada en Ceneral Pico en 1937, uno de los años más duros -como vimos- en lo que respecta a la sequía. Según relataba de manera retrospectiva Joaquín Vidal, quien ingresó como empleado a Industrias Maracó en los años cincuenta y luego alcanzó un cargo directivo, la iniciativa había surgido de José Viscardis y los hermanos Juan y Enrique Bastard. El primero de ellos, llegado desde Santa Fe junto con su padre (que era herrero al igual que José), tenía un taller y se dedicaba a la herrería. El inicio de la actividad vinculada con la mecánica agropecuaria tuvo lugar a raíz de los inconvenientes causados por la tucura, que por ese entonces era un "problema serio". ${ }^{16}$ Para combatirla, comenzaron a fabricar "una herramienta consistente en unos platos con púas, muy pesados -cultivadores de

15 La localidad de Anguil se encuentra a escasa distancia de Santa Rosa, la capital pampeana, y su ubicación se puede observar en la imagen 1 que incluimos previamente.

16 En efecto, la invasión de langostas había sido una de las "plagas" que afectó al TNLP en la década del treinta, a la que se sumaron la sequía intensa, los fuertes vientos, la caída de ceniza volcánica, las heladas tardías, los incendios de grandes extensiones de campos naturales y montes, entre otros factores adversos para el desarrollo socioeconómico, según el relato de un contemporáneo (Colombato, 1998). 
alfalfa lo llamábamos-, que se pasaba sobre el campo y removía la tierra a una profundidad deseada en relación al desove [de la tucura], que quedaba expuesto al menos más arriba". Cuando la hacienda pisaba el suelo, contribuía a destruir los huevos, lo que reducía la reproducción. De acuerdo al relato de Vidal, fabricaban también cocinas de leña y bombas extractoras de agua para perforaciones, pero a inicios de la década del cincuenta se popularizaron en la zona las cocinas de querosén y los bombeadores eléctricos, razón por la cual "se planteó un momento crítico" para la empresa, que era una Sociedad de Responsabilidad Limitada. Por esos años, poco antes de promediar la década, Juan y Desiderio Echeverz Harriet se incorporaron a Industrias Maracó; el primero de ellos era yerno de José Viscardis, quien les había propuesto ingresar a la firma y fabricar maquinaria agrícola. ${ }^{\mathbf{1 7}}$

Si bien ya desde fines de la década del cuarenta allí se producían este tipo de maquinarias diseñadas para trabajar en suelos áridos y semiáridos, fue a partir de la incorporación de los hermanos Echeverz Harriet, dedicados a la producción agropecuaria en sus propias explotaciones, que se hicieron importantes avances en ese sentido. Durante la época en la que estos productores se sumaron a la empresa, de acuerdo a la información brindada por la prensa local, Industrias Maracó ocupaba una superficie de 1.800 metros cuadrados, de los cuales 1.200 eran cubiertos, y trabajaban allí 50 obreros. Entre las máquinas con las que contaba el establecimiento había tornos, cepilladoras, limadoras, agujereadoras, sierras mecánicas, una prensa hidráulica de 150 t y una tijera punzonadora Weingarthen. Estas dos últimas habían sido adquiridas recientemente con el objetivo de incrementar la producción de arados: se pensaba llegar de 30 a 50 unidades mensuales, ya que tenían "inmediata colocación apenas puestos en venta”. Además, en la nota periodística destacaban que, en el depósito, la empresa tenía 100.000 kg de acero para la confección de arados, 60.000 kg de ángulo para sus armazones y 800 metros de caños de acero, a lo que se le agregaban 2.700 discos importados en el puerto, 12.000 bolilleros que estaban por recibir -también de importación-, y que el Banco Central le había otorgado el permiso para importar los materiales necesarios para completar 500 arados. Según advertían, el "renglón más importante" de la fábrica era la producción de estos últimos, aunque también habían comenzado a fabricar clavadoras de cajones, una de las cuales estaba exhibida en el frigorífico Anglo "para darla a conocer". En cuanto a los arados, había de dos tipos: el arado rastra I.M.2.B (pesado), que ya estaba patentado, y el arado rastra I.M.1.B (liviano), cuya patente estaba aún en trámite. Estos productos tenían ruedas neumáticas o de hierro, levante automático y cajón sembrador de granos finos y maíz, entre otras características positivas, y contaban a su vez con la aprobación de los usuarios de acuerdo a "las referencias de agricultores que los han utilizado". En su construcción, el asesoramiento técnico había estado a cargo de los Echeverz Harriet, productores que se caracterizaban "por su espíritu

17 La Arena, 6 de diciembre de 1980, n. ${ }^{0} 11.111$, Santa Rosa. 
progresista". Efectivamente, Desiderio había realizado viajes frecuentes a Estados Unidos y, posteriormente, a Japón para "interiorizarse de los últimos adelantos en maquinaria agrícola". ${ }^{18}$ No obstante, nada se decía aún sobre el potencial que tenía la producción de esa industria en términos de conservación del suelo, debido a razones que analizaremos más adelante.

En la misma nota en la que ofrecían toda esa información sobre la situación de la empresa en 1954, daban cuenta del interés del Cobierno provincial por el desarroIlo de la fábrica, así como también de las autoridades de provincias vecinas. Como se puede apreciar en la fotografía insertada en el medio de prensa, el gobernador peronista Salvador Ananía había recorrido Industrias Maracó y observado su producción junto con su par de San Luis, provincia que también había sido afectada por el proceso erosivo. ${ }^{19} \mathrm{~A}$ su vez, según veremos con detalle en el apartado siguiente, los funcionarios de Ananía (en especial, los de la Subsecretaría de Asuntos Agrarios) solían visitar los campos de los Echeverz Harriet para observar cómo llevaban a cabo algunas labores, tomar nota de las experiencias e informarse sobre los futuros productos que proyectaba fabricar Industrias Maracó. Sin embargo, al parecer, la empresa no recibió apoyo crediticio durante el peronismo, en un marco en el que la distribución del crédito en el interior del país no estuvo entre las prioridades del Banco de Crédito Industrial (Girbal-Blacha, 2003). Lo que sí resulta evidente es que, para el Cobierno de Ananía, esta industria era relevante en el contexto provincial. Por su parte, seguramente la empresa se benefició del contexto, si tenemos en cuenta la información brindada anteriormente sobre la posibilidad de importar materia prima. En particular, debido a que, luego de una etapa inicial en la que el Cobierno de Juan D. Perón impulsó la importación de maquinaria agrícola, el Estado llevó a cabo por primera vez una política que sentó las bases para el desarrollo del sector. Desde fines de los años cuarenta, el Banco Central estableció prioridad de cambio para maquinarias agrícolas, pero la orientación importadora se modificó en 1951, cuando se declaró de "interés nacional" la industria de maquinarias e implementos agrícolas. Desde ese momento, se dio paso a la política oficial de promoción industrial mediante cuotas de importación para los productos que competían con los fabricados en el país, exención de derechos sobre maquinarias y permisos de cambio para adquirirlas (Belini, 2009, pp. 90-99). Al mismo tiempo -de acuerdo a lo que plantea Noemí Girbal-Blacha (2003, p. 50)-, con la "vuelta al campo" se implementó, además, una política de créditos más favorable para el sector agropecuario y, desde los años cincuenta, el sistema bancario aumentó el apoyo crediticio a favor de la reactivación del agro, rebajó los intereses de las operaciones, generalizó el crédito rural de habilitación (de bajo interés y largo plazo de reintegro) y acordó, también, créditos preferenciales a las cooperativas. Es en esta coyuntura en la que

18 La Reforma, n. ${ }^{\circ} 8.615,31$ de diciembre de 1954, Ceneral Pico. 
Industrias Maracó pretendía aumentar la producción de arados de 30 a 50 unidades mensuales porque tenían colocación "inmediata".

Por esos años, el Gobierno nacional concretó la instalación de instituciones que desde hacía tiempo eran reclamadas por las autoridades locales. Se creó una Escuela de Agricultura y Ganadería (EAyC) en Victorica en 1952, ${ }^{20}$ destinada a formar peritos rurales con orientación ganadera y forestal, y la EEA en Anguil en 1954, que se convertiría progresivamente en una referencia para el centro de la Argentina en manejo de pasturas, estudios sobre el suelo y búsqueda de métodos adecuados para prevenir la erosión. ${ }^{\mathbf{2 1}}$ Como veremos aquí, el vínculo entre Industrias Maracó y los especialistas que trabajaban en la EEA, en especial con los Echeverz Harriet, fue asiduo. La EEA había sido creada con objetivos específicos, y esto permitió que la Institución estuviera en directa relación con los principales conocedores de la temática en Argentina: los técnicos del ISyA. Por cierto, fueron ellos quienes Ilevaron a cabo el relevamiento del área donde se instalaría la EEA, entre algunos podemos mencionar a los ingenieros agrónomos de la División de Conservación y Mejoramiento de Suelos del ISyA: Antonio Prego, Luis A. Tallarico, Carlos A. Bellón y José E. Calcagno. En el informe señalaban que, en el reconocimiento realizado por esta agencia estatal entre 1944 y 1945, una parte del sector pampeano se incluyó en la zona IV, caracterizada por presentar una "erosión severa a grave". Las variaciones en el grado de la erosión obedecían al tratamiento que habían recibido los suelos, por eso afirmaban: "Labranzas repetidas con instrumentos inapropiados realizadas a destiempo, cultivo de especies no adaptadas al lugar y sobre pastoreo, resumen las causas de la erosión presente" (Prego, Tallarico, Bellón y Calcagno, 1955, p. 10). Entre las cuestiones que desvelaban con igual intensidad a los hermanos Echeverz Harriet y a los técnicos de la EEA, se destacaba el interés por encontrar alternativas que les permitieran a los productores agropecuarios labrar el suelo con implementos adecuados a las condiciones erosivas de la región y aplicar prácticas para conservarlo.

El director de la EEA era el ingeniero agrónomo Guillermo Covas, que se había formado en la Universidad Nacional de La Plata (UNLP) y había llegado a la provincia con el objetivo de ponerse al frente de la Institución. ${ }^{22}$ Para ese entonces, él también había realizado un posgrado en la Universidad de California (Berkeley, Es-

20 La localidad de Victorica se encuentra ubicada al noroeste de Santa Rosa, en la zona centro-oeste del espacio provincial (Departamento Loventué).

21 Como no es posible extendernos aquí, remitimos a Martocci (2018) para ampliar sobre las actividades desplegadas por ambas instituciones en sus momentos iniciales.

22 Covas obtuvo su título de grado en la UNLP en 1935 y luego se insertó laboralmente en el Instituto Experimental de Investigación Agrícola de la provincia de Santa Fe. Además, a fines de esa década ingresó como docente en la Facultad de Agronomía de la UNLP. A inicios de los años cuarenta se radicó en Mendoza y fue profesor en la Universidad Nacional de Cuyo, y en 1947 comenzó a trabajar en el Instituto de Fitotecnia de Castelar. Además de su tarea como director de la EEA, a partir de 1958 también tuvo un rol clave en la organización inicial de la Facultad de Agronomía de la Universidad de La Pampa y fue docente en esta Institución. 
tados Unidos), financiado con una beca otorgada por la Asociación Argentina para el Progreso de las Ciencias, que le permitió especializarse en Biosistemática. La estadía en ese país seguramente le sirvió a su vez para familiarizarse con los adelantos en materia de conservación del suelo, ya que-como apuntamos antes-esta nación había experimentado una extraordinaria crisis erosiva en la década del treinta y, a comienzos de los años sesenta, sus técnicos continuaban siendo una referencia en la materia para los especialistas en otros países de América. Con la creación del INTA, la EEA se convirtió en la dependencia más importante de este organismo en La Pampa, en especial gracias a sus aportes en cuanto a la conservación de la humedad en el suelo y la búsqueda de prácticas agrícolas para prevenir la erosión. El ingeniero agrónomo Antonio Cairnie, uno de los integrantes del primer staff de la EEA, recuerda que los hermanos Echeverz Harriet -según él, productores "de avanzada"- eran amigos de Covas y visitaban frecuentemente la EEA. A su vez, señala que los técnicos de esta última también viajaban a los campos que los integrantes de Industrias Maracó tenían en la zona de General Pico con el fin de ir "a aprender". Es decir, la relación era claramente interactiva, aunque Cairnie afirma que Covas a veces "le recomendaba lo que había que hacer" a Industrias Maracó. De acuerdo con su testimonio, el rastrón poceador "fue una cosa que le sugirió Covas" a esa empresa. ${ }^{\mathbf{2 3}}$ Esta herramienta fue difundida por la EEA a fines de la década del cincuenta mediante la publicación de dos circulares de extensión en las que se abordaban sus cualidades. ${ }^{\mathbf{2 4}}$ En la primera de ellas, advertían que el rastrón poceador era una adaptación originada en Estados Unidos: el personal de la Estación Experimental de Archer, junto con técnicos de una fábrica de maquinaria agrícola, introdujeron una modificación al arado-rastra y alternaron los discos para que quedaran insertos algunos de manera centrada y otros en posición excéntrica. Así, cuando surcaba el suelo, dejaba una superficie "poceada y áspera", con una importante cobertura de rastrojo, de modo tal que prevenía la erosión por el viento y evitaba el escurrimiento superficial de agua (Covas y Knudtsen, 1958). En el apartado siguiente ampliaremos la información al respecto.

Sin embargo, los Echeverz Harriet interactuaban también con otros especialistas y tenían autonomía en la toma de decisiones, así como en la búsqueda de información y de conocimientos generados en otros países, lo que les permitía experimentar en sus explotaciones y obtener sus propios resultados. Ya en la década del sesenta, Covas afirmaba que uno de los hermanos integrante de Industrias Maracó había traído a la Argentina el pasto llorón (Eragrostis curvula, una pastura de origen africano con potencial conservacionista) luego de un viaje a Estados Unidos, país en el que había sido ensayada y difundida previamente. ${ }^{25}$ Este ingeniero agrónomo

23 Entrevista a Antonio Cairnie.

24 Véase Covas y Knudtsen (1958) y Covas y Sarasola (1966).

25 Zona Norte, n. ${ }^{\circ}$ 5, 1966, General Pico, s/n. 
era un especialista en dicho pasto, recomendado por la EEA con fines forrajeros y para fijar el suelo y prevenir la erosión eólica. Por esos años, inclusive los campos de los Echeverz Harriet eran frecuentados por estudiantes de Ingeniería Agronómica: Jorge Molina, docente de la asignatura Agricultura Ceneral en la Facultad de Agronomía de la UBA, llevó a sus alumnos a un establecimiento que estos tenían en la provincia de Buenos Aires, donde pudieron observar el plan de rotación que ellos utilizaban y la maquinaria que empleaban. Al intercambiar con los productores, se ponía de manifiesto que los Echeverz Harriet estaban al corriente de las recomendaciones del INTA, ya que afirmaban que el pasto llorón no engordaba pero permitía mantener a la hacienda de cría en invierno, función que también podía cumplir el agropiro alargado. Los terrenos medanosos de esa explotación, según el relato, estaban cubiertos con pasto Ilorón; y además agregaban: "Ahora Industrias Maracó prepara una sembradora especial para estas y otras semillas diminutas". ${ }^{\mathbf{6}}$ Como puede advertirse, los ensayos que hacían en sus campos a veces derivaban en ideas originales e innovaciones para fabricar nuevos productos en la empresa del norte pampeano. Y al mismo tiempo, interactuaban con sus pares, es decir, con otros productores, hasta dieron charlas en zonas rurales sobre mecanización agrícola que fueron tomadas como referencia por los especialistas del INTA. ${ }^{\mathbf{2 7}}$ De esta manera, estaban en condiciones de posicionarse como agentes innovadores que partían de sus ensayos para idear implementos y herramientas útiles para la región semiárida, pero también como actores que contribuían en la tarea de difundir los productos de Industrias Maracó.

Al promediar la década del sesenta, según otros estudios, esta fábrica se contó entre las empresas metalúrgicas de Ceneral Pico beneficiadas con créditos destinados a la promoción industrial, en consonancia con los objetivos que se proponía entonces el Cobierno provincial de Ismael Amit (Cantera, 2017, pp. 144-145). Desde su gestión, este referente local de la Unión Cívica Radical Intransigente (UCRI) pretendió impulsar el desarrollo integral de los sectores agropecuario, minero e industrial (Lluch y Comerci, 2011), de allí la importancia de esa industria del norte pampeano que contribuía a tecnificar el agro. Asimismo, el acceso de la empresa al apoyo crediticio se dio en un contexto en el que los implementos agrícolas que producía Industrias Maracó adquirían cada vez mayor difusión en el agro pampeano, situación favorecida, sin duda, por su relación con la EEA del INTA y por la relevancia que estaban asumiendo en la Argentina y otros países de América el tema de la conservación del suelo y los estudios sobre la producción en regiones semiáridas, como señalamos previamente. En ese entonces, el gobernador Amit destacaba la incorporación de implementos agrícolas por parte de los productores, sobre todo de los arados, que eran justamente uno de los principales productos fabricados

26 Zona Norte, n. ${ }^{\circ} 4,1966$, General Pico, s/n.

27 Véase Itria (1969, p. 60). 
por Industrias Maracó: según el mandatario, en 1960 había 6.323 arados, cifra que ascendió a 7.424 en 1964 (Amit, 1965, p. 10). A partir de esa década, esta empresa de Ceneral Pico se posicionaría como una referencia en herramientas agrícolas de carácter conservacionista, hecho que es imposible de explicar sin prestar la debida atención a la circulación (nacional y transnacional) de saberes y a las relaciones de la empresa con otros actores.

\section{Implementos agrícolas conservacionistas: interacciones y circulación de saberes}

De acuerdo con la información analizada, y según las referencias de actores de la época, los hermanos Echeverz Harriet no solo tenían la posibilidad de viajar y conocer prácticas agrícolas en otros países, sino también de ensayar con cultivos y herramientas en sus explotaciones, algunas de ellas localizadas en la región semiárida. Se destacan los viajes de Desiderio a los Estados Unidos, un país que había experimentado un complejo proceso erosivo también en la década del treinta, lo que Ilevó a su Gobierno a tomar medidas para afrontar esa problemática. Las medidas fueron más inmediatas en comparación con las implementadas en la Argentina, donde recién en 1944 se puso en funcionamiento el ISyA y se profundizaron los relevamientos y estudios sobre el proceso erosivo. Ante esa situación, no es extraño que actores del sector privado se familiarizaran con los adelantos técnicos alcanzados en otros lugares. El propio Covas afirmaba -como vimos-que ya a inicios de los años cuarenta, los Echeverz Harriet habían introducido el pasto llorón en Argentina, sin lugar a duda porque estaban al corriente de los ensayos realizados en Estados Unidos con esa pastura africana. Asimismo, los hermanos que integraban Industrias Maracó interactuaban con funcionarios y técnicos estatales, como advertiremos a continuación.

En 1955, por ejemplo, el ingeniero agrónomo Rafael Silberman, quien entonces era director de Defensa de la Producción Agropecuaria y luego sería extensionista en la EEA, relataba en una publicación editada por el Cobierno provincial la visita que habían realizado con el subsecretario de Asuntos Agrarios, César P. Ballari, a un campo de Juan Echeverz Harriet ubicado en el oeste bonaerense (Partido de Rivadavia). En su nota, Silberman (1955, pp. 9-10) se concentraba en un método nuevo para combatir la tucura que se estaba ensayando en ese establecimiento, basado en la aplicación del insecticida "dieldrin", y que había provocado una muy buena impresión a los visitantes pampeanos, quienes se encargarían de informarlo a las autoridades provinciales. A su vez, Silberman mencionaba que, para esparcir este producto, se podría emplear un pico pulverizador que los Echeverz Harriet estaban confeccionando en Industrias Maracó. Como ya observamos, esta empresa era importante para el gobernador Ananía, quien organizaba visitas oficiales y recorría las instalaciones junto a otros mandatarios. Sin embargo, de acuerdo a la evidencia, 
también los principales funcionarios del área de Asuntos Agrarios se vincularon con los Echeverz Harriet durante la gestión del gobernador peronista y solían observar los ensayos en las explotaciones que ellos tenían, los que a su vez les permitían desarrollar nueva tecnología desde la empresa. Esto ocurría en un contexto en el que para la gestión de Ananía, quien asumió en 1953, la conservación del suelo tenía gran relevancia. Durante su mandato se aprobaron leyes específicas con objetivos conservacionistas; inclusive, en el mismo número de Agro Pampeano -en el que apareció la nota de Silberman-publicaron una de Antonio Prego, que trataba la cuestión del almacenamiento del agua en el suelo, un aspecto fundamental en la región debido a la variabilidad en el régimen de lluvias. Allí, por ejemplo, recomendaba que, luego de la cosecha, se llevara a cabo el cultivo bajo cubierta a fin de favorecer la penetración en el suelo del agua de lluvia estival, así como también la no pulverización de la superficie del suelo para evitar la erosión eólica. En La Pampa (por entonces denominada provincia Eva Perón), el sur de Córdoba y el oeste bonaerense era clave, según este técnico del ISyA, dejar los campos con superficie "terronosa" y cobertura vegetal para impedir el escurrimiento del agua y favorecer, así, una mayor penetración en el suelo (Prego, 1955, p. 10).

La búsqueda de este tipo de prácticas era uno de los principales objetivos de la EEA, que ya en sus primeros años difundía en sus circulares de extensión recomendaciones al respecto. Uno de sus técnicos recordaba en una de ellas la importancia de no olvidar (en años climáticamente benignos) "el agudo problema de la movilización del suelo por los vientos", ya que no había desaparecido "el peligro de los desastres que provocan los períodos prolongados de sequía", como en 1937 o entre 1949 y 1951. Era preciso, entonces, que el agua penetrara en el suelo a una mayor profundidad a fin de evitar la evaporación, razón por la cual había que labrar el suelo de manera oportuna y adecuada. Una vez levantada la cosecha, de inmediato debía labrarse el suelo con un arado rastra (llamado también rastrón) o, mejor aún, con un rastrón poceador. De esta manera, quedaba una superficie "terronosa" y cubierta con residuos vegetales, lo que aminoraba el efecto erosivo y desecante de los vientos intensos. Así, se lograba un barbecho estacional, de tres a cuatro meses, que reunía muchas ventajas, como ya habían demostrado también las experiencias realizadas en Estados Unidos. Además, el empleo de las herramientas mencionadas (en especial, el rastrón poceador) dejaba aproximadamente un $60 \%$ de los residuos vegetales entremezclados en la superficie del suelo, con las ventajas que eso implicaba (Pose Rodríguez, 1959). El rastrón poceador, llamado también arado de discos excéntricos (imagen 2), era un implemento que tenía su origen en la experiencia norteamericana y, según los especialistas de la EEA, mejoraba las funciones del arado rastra porque, si la cobertura original no era densa o se reiteraba la labranza, el suelo podía quedar expuesto a la erosión o al "planchado" si caían Iluvias intensas. 
Imagen 2. Rastrón poceador (o rastrón de discos excéntricos)

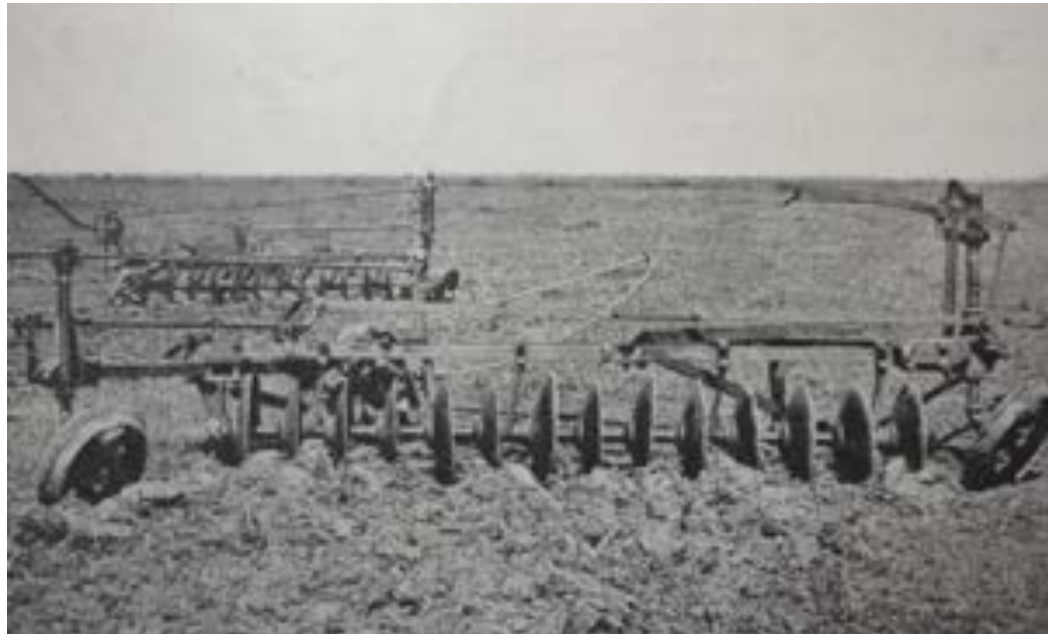

Fuente: Agronales, n. ${ }^{\circ}$ 2, enero-abril, 1959, p. 3.

Con la superficie poceada eso se prevenía, aunque no se percibían mejoras apreciables en cuanto al rendimiento de grano o pasto. A fines de la década del cincuenta ya eran ampliamente difundidas por la EEA las ventajas del rastrón poceador, lo que permite intuir el interés de los productores por una herramienta con esas características, más aún teniendo en cuenta que-como se afirmaba en la circular-hacia 1958 no se hallaban disponibles en el mercado nacional discos de arado con la abertura fuera de centro, por eso los productores debían apelar a sus habilidades para adaptarlos (Covas y Knudtsen, 1958). Esta herramienta, desde luego, debía reemplazar al arado de vertedera (denominado también de reja), que removía completamente la superficiey así favorecía la erosión. Por estas razones, e indudablemente gracias a los conocimientos sobre las experiencias norteamericanas, el propio Covas le habría sugerido a Industrias Maracó la confección del rastrón poceador, según recuerda -como vimos- un ingeniero agrónomo que trabajaba en ese momento en la EEA. Es factible que los Echeverz Harriet tomaran con buena disposición la recomendación, ya que también conocían de cerca los avances de Estados Unidos en materia de conservación del suelo. Este país era claramente, y lo seguiría siendo en las décadas siguientes (Alapin, 2008), un referente importante en ese sentido: además del pasto llorón, la EEA difundía otros cultivos perennes para establecer pasturas permanentes en la región semiárida que habían sido ensayados antes en Estados Unidos, por ejemplo, la festuca alta (originaria de Europa y Asia) y el panizo azul (originario del sur de Asia y Australia). ${ }^{\mathbf{2 8}}$

Al mismo tiempo, la introducción de este tipo de cultivos a la región motorizaba la necesidad de producir nueva tecnología, tal es el caso de la sembradora para se-

Al respecto, ver Covas (1958 y 1969). 
millas muy pequeñas (como las de pasto llorón) que preparaba Industrias Maracó al promediar los años sesenta. Algo similar ocurrió con el rastrón poceador, ya que para la segunda mitad de esa década los técnicos de la EEA afirmaban que su empleo había "superado la etapa experimental, habiendo empezado a ser utilizado por productores de la región con éxito notable". Sin embargo, agregaban que se debía evitar repetir las aradas con ese rastrón en suelos muy expuestos a la erosión eólica. Recomendaban, en cambio, usar el arado de discos excéntricos como labranza básica y, luego, mantener el barbecho limpio mediante labores complementarias con arado "pie de pato" o barras escardadoras (Covas y Sarasola, 1966), el primero de ellos fabricado por Industrias Maracó. La EEA realizaba ensayos en campos de agricultores con rastrón poceador y barras escardadoras ya a fines de la década del cincuenta en Ceneral Pico y Metileo (al norte de La Pampa), pero también en las zonas de Henderson, Trenque Lauquen, Ceneral Villegas y Pehuajó (en provincia de Buenos Aires), para demostrar la "superioridad del barbecho" y del laboreo que dejaba residuos vegetales en la superficie. ${ }^{29}$ Como puede verse, la introducción de un implemento similar al usado en Estados Unidos no resolvía por completo la situación y había que complementar con otros para labrar el suelo con un criterio conservacionista.

Desde luego, las iniciativas y los métodos para conservar el suelo eran tomados (y adaptados) en cierta medida de experiencias foráneas, especialmente de las norteamericanas. Así lo reconocían los propios especialistas: por un lado, Julio Ipucha Aguerre afirmaba que, para proyectar los primeros planes de acción del ISyA, fue preciso recurrir a la experiencia de Estados Unidos, "un país que venía reaccionando de modo admirable frente a los estragos que la erosión provocara en su vasto territorio" (Ipucha Aguerre, 1964, p. 6); por otro lado, Walter Kugler, en un discurso pronunciado en 1963 como secretario de Agricultura y Ganadería de la Nación, señalaba que la técnica del cultivo bajo cubierta se había desarrollado en las grandes planicies norteamericanas "luego de la desastrosa sequía que sufrieran en la década del 30", lo que les permitió aminorar el impacto de la sequía que azotó al medio oeste de Estados Unidos entre 1950 y 1954 (Kugler, 1964, p. 61). No obstante, detrás de esas imitaciones había un carácter activo, tal como se observa en el relato de un integrante de Industrias Maracó sobre la posibilidad de integrar funciones en los implementos agrícolas. Al respecto, Joaquín Vidal -a quien ya nos referimosdécadas después planteaba lo siguiente sobre el papel de los Echeverz Harriet y la producción de la empresa.

Como ellos [los Echeverz Harriet] estaban muy al tanto de la técnica agropecuaria en los EEUU buscaron herramientas adecuadas a este suelo e importaron algunos arados de rastra pero como por entonces, 1951, no era fácil importar se comenzó a estudiar la idea de fabricar un arado de ese tipo pero como los norteamericanos se

Agronales, n. ${ }^{\circ}$ 2, enero-abril, 1959, pp. 1-4. 
oponían a la ubicación de un cajón sembrador sobre el arado de rastra, porque no son partidarios de esa siembra, prácticamente a voleo, esa circunstancia nos obligó a fabricar nosotros mismos un equipo de siembra y de allí nació el Mínima Labranza. ${ }^{30}$

Tal como se advierte en sus palabras, el ejemplo foráneo desempeñó un rol importante, pero eso no alcanza, sin embargo, para explicar el proceso de innovación técnica en la región semiárida. Esto explica la aparición de maquinaria específica, como la denominada sembradora "mínima labranza Maracó", fabricada en Ceneral Pico y que presentaba un sistema de control de profundidad de siembra y compactación de los surcos sembrados (imagen 3). Vidal se ocupaba de aclarar: "La Mínima Labranza es una invención de Maracó". 31 Esta herramienta estaba bien conceptuada por los ingenieros agrónomos del INTA, según quienes se adaptaba de manera apropiada para la siembra combinada de distintas especies, como la alfalfa y el centeno (Itria, 1969, p. 20). ${ }^{32}$

Imagen 3. Sembradora "mínima labranza Maracó"

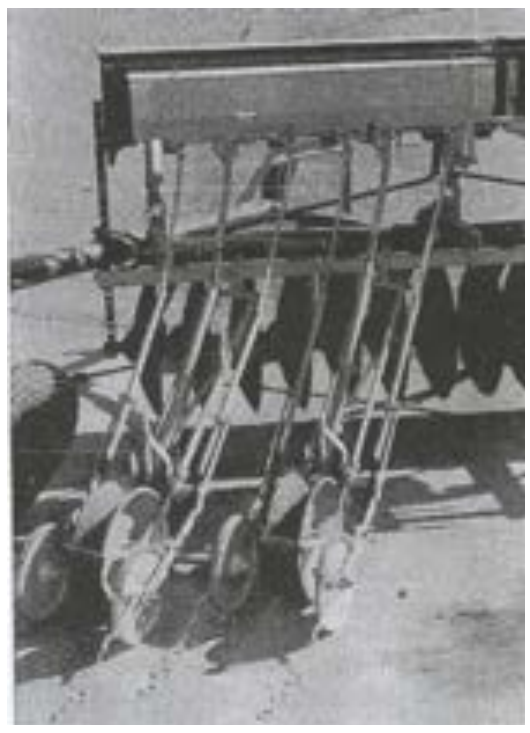

Fuente: Itria (1969, p. 20).

Asimismo, mejorar la labor de las sembradoras había sido un tema relevante para la EEA, de hecho, desarrollaron dispositivos con esta finalidad que se aplicaban a la siembra de cereales y de especies forrajeras de semilla pequeña. Entre ellos, se

30 La Arena, 6 de diciembre de 1980, n. ${ }^{\circ} 11.111$, Santa Rosa.

31 La Arena, 6 de diciembre de 1980, n. ${ }^{\circ} 11.111$, Santa Rosa.

32 Cabe agregar que, en la misma página donde insertaban una imagen de la sembradora fabricada por Industrias Maracó, incluían una foto del sistema de implantación de alfalfa y centeno que empleaba una explotación de Echeverz Harriet ubicada en el oeste bonaerense. Ver Itria (1969, p. 20). 
destacaban las ruedas compactadoras y reguladoras de la profundidad de siembra, que habían sido diseñadas por el ingeniero agrónomo Juan C. Ferrando, de la EEA, y eran más eficientes que el "patín" ideado por un productor de la zona de Bolívar (Buenos Aires). ${ }^{33}$ Este tipo de dispositivo introducía modificaciones a las sembradoras convencionales y permitía utilizar una menor cantidad de semillas y obtener una germinación rápida y uniforme, en un contexto en el que el exceso de semillas por hectárea podía insumir una mayor cantidad de humedad y agotar las reservas acumuladas en el suelo mediante prácticas agrícolas específicas, como las que detallamos antes. La sembradora "mínima labranza Maracó" también compactaba los surcos sembrados, práctica que era recomendada por la EEA para preservar el suelo y ajustar la profundidad de siembra más apropiada en función de las especies. Al finalizar la década del sesenta, los aportes de Industrias Maracó en materia de innovación eran positivamente valorados por la revista Huallquitun, publicada por la Agencia de Extensión Rural del INTA en Ceneral Pico. Allí planteaban, por ejemplo, que el rastrón podía convertirse en una "eficiente sembradora" y también agregaban: "Industrias Maracó ha convertido a este implemento, uno de los más generalizados en el medio rural, en un verdadero bastidor porta-herramientas". De esta manera, al perfeccionar el sistema de siembra y al acoplar la rueda compactadora, el productor podía "realizar la roturación y siembra [en] simultáneo ('mínima labranza')", en especial aplicada en cultivos estivales "con muy buenos resultados". Asimismo, para ese entonces se había perfeccionado esta característica mediante el agregado, por un lado, del sistema Lister (que prevenía la erosión) y, por otro, del sistema de siembra a surco profundo (que era el más indicado para la siembra de cereales). ${ }^{\mathbf{3 4}}$

Vidal relataba a la prensa que, en los albores de la década del ochenta, había unas 75.000 sembradoras mínima labranza fabricadas por la empresa pampeana trabajando en todo el país. Y, a partir de otra pregunta, añadía que la "tendencia constante" de Industrias Maracó había sido "primero, cuidar el suelo de la erosión eólica (por eso jamás fabricamos un arado de reja) y luego eficiencia y economía".35 El agrónomo Hugo Catalani, técnico de la Agencia de Extensión Rural del INTA de General Pico y director de Huallquitun, confirma este planteo y recuerda que esa empresa llegó a tener muchísimo "prestigio" entre los productores. Esto se debía, según él, a que "sacaban un tipo de máquinas que, para la realidad agronómica del momento, andaba muy bien y era barata". Para que esto ocurriera-agrega el extensionista del INTA-, era esencial el rol que desempeñaba Desiderio Echeverz Harriet, cuyo campo era "un lujo". ${ }^{36} \mathrm{Al}$ igual que Cairnie, empleado de la EEA, Catalani pone de relieve el papel de estos productores innovadores integrantes de la firma que

33 Ver Covas (1963).

34 Huallquitun, n. ${ }^{6}$ 6, año II, septiembre-octubre, 1970, General Pico, pp. 5-6.

35 La Arena, 6 de diciembre de 1980, n. ${ }^{\circ} 11.111$, Santa Rosa.

36 Entrevista a Hugo Catalani. 
fabricaba maquinaria agrícola, quienes evidentemente tenían un vínculo estrecho con los técnicos estatales. Estos últimos reconocían, de acuerdo con los artículos de Huallquitun, los aportes de Industrias Maracó en cuanto a la conservación del suelo y la búsqueda de alternativas para producir en la región semiárida.

Es claro que los Echeverz Harriet y los trabajadores de algunas dependencias del INTA en la provincia compartían un mismo "marco tecnológico", es decir que partían de conceptos, técnicas y conocimientos similares o complementarios, que se disponían a ensayar y contrastar experiencias, e incluso interactuaban entre ellos a fin de alcanzar resultados, ya que los primeros frecuentaban la EEA, por ejemplo, y la gente del INTA (según recuerda uno de ellos) solía visitar las explotaciones de los hermanos Echeverz Harriet para observar sus experiencias. De este modo, se evidencia el carácter interactivo en la producción de conocimientos, pero también en el plano de la búsqueda de maquinarias e implementos agrícolas aptos para labrar y cultivar en una región que, durante los años treinta y cuarenta (incluso a inicios de los cincuenta), había sido muy fuertemente afectada por la sequía y la erosión. Así, la interacción a partir de un marco tecnológico compartido permite explicar mejor la emergencia de ciertos artefactos con características específicas y, a su vez, cómo estos últimos intervinieron en un contexto en el que la problemática erosiva era un tema de investigación en las agencias científico-técnicas y un aspecto relevante en las agendas de los gobiernos provincial y nacional. Antiguos dueños de Industrias Maracó daban cuenta de ese vínculo, de manera retrospectiva, cuando afirmaban: "En la época que nos tocó vivir caminábamos muy de la mano con el INTA. [...] Hablábamos el mismo idioma..." (citado en INTA, 2009, p. 16).

A poco de cumplir cuarenta años de existencia, en 1977, uno de los principales diarios de La Pampa publicaba una nota sobre Industrias Maracó, cuyo subtítulo rezaba: "Trabajar bien la tierra es un deber social". Allí destacaban su producción de rastras de distinto tipo y sembradoras, pero también del "pie de pato", que prevenía la erosión del suelo. Insistían en que los implementos fabricados se lanzaban al mercado luego de las respectivas pruebas en suelos de diferentes características estructurales. Para entonces, la comercialización tenía un amplio campo de acción, que incluía La Pampa, el sur y el centro de Santa Fe y Córdoba, Buenos Aires, el este de San Luis y el norte de Río Negro, aunque también sus productos Ilegaban a Santiago del Estero, Entre Ríos, Mendoza, San Juan, Catamarca, Tucumán, Jujuy, Chaco y Formosa. ${ }^{37}$ Algunos años después, durante la última dictadura cívico-militar, la empresa obtuvo el Premio al Mérito Agropecuario, que también fue otorgado a profesionales, productores, cooperativas e instituciones del medio vinculadas con la producción agropecuaria. Para ese entonces, un integrante de Industrias Maracó señalaba que habían exportado producción a Uruguay y Paraguay. Resulta claro cuál era uno de los principales logros de la firma galardonada, puesto que en la nota que apareció

La Arena, 7 de abril de 1977, n. ${ }^{\circ} 10.077$, Santa Rosa. 
en la prensa titulaban: "La industria al servicio del conservacionismo". ${ }^{38}$ Más aún, en ese momento, sus integrantes eran reconocidos como "precursores de la mínima-labranza", en un contexto en el que la empresa contaba con nuevas y más amplias instalaciones en el Parque Industrial de General Pico, y ocupaba a unas 180 personas. ${ }^{39}$

El ascendiente de Industrias Maracó entre los productores de la zona norte de La Pampa se conserva, en parte, hasta la actualidad, a pesar de que la empresa entró en crisis en el último tercio de la década del ochenta (en un difícil contexto macroeconómico) y quebró a inicios de la siguiente por razones que ya fueron analizadas a partir de la historia económica..$^{\mathbf{4 0}}$ Un productor agropecuario de General Pico no duda en afirmar que esta fue una "empresa líder" que "colaboró mucho" haciendo herramientas adecuadas para el manejo del suelo. Y agrega: "hasta no hace mucho todavía venían [a Ceneral Pico] de San Luis a buscar rastrones usados que se fabricaban en esos años". ${ }^{\mathbf{1 1}}$ No es difícil creer estas palabras si tenemos en cuenta que, como advertimos aquí, ya al promediar el siglo XX, cuando Industrias Maracó se orientó a la producción de implementos agrícolas, los gobernadores de la provincia Eva Perón y de San Luis recorrían juntos la planta de esa empresa para conocer lo que allí se fabricaba. Indefectiblemente, la crisis generada por la sequía y la erosión entre los años treinta y cuarenta permitió queuna empresa como esta tuviera un amplio campo de acción en todo el centro del país.

\section{A modo de cierre}

En este trabajo procuramos demostrar que, para explicar la aparición de prácticas y herramientas agrícolas tendientes a la conservación del suelo, es fundamental atender a las décadas del cuarenta y el cincuenta, puesto que en los años treinta el proceso erosivo había afectado a una extensa región del centro del país. Esto incidió en el despliegue de acciones desde el ámbito estatal, pero también en las iniciativas del sector privado, tal es el caso de Industrias Maracó. Esta empresa, especializada en la producción de implementos agrícolas desde los años cincuenta, contaba con la valiosa participación de los hermanos Echeverz Harriet, quienes, además de integrar la firma, tenían sus propias explotaciones agropecuarias donde ensayaban con prácticas utilizadas en los Estados Unidos, experimentaban con métodos que ellos mismos ideaban y, al mismo tiempo, probaban las herramientas que se fabricaban en Industrias Maracó. La relación entre estos productores y los técnicos del INTA generó una sinergia que permitió crear implementos para trabajar el suelo con criterios conservacionistas, por ejemplo, el rastrón poceador, el "pie de pato" y

\footnotetext{
38 La Arena, 6 de diciembre de 1980, n. ${ }^{\circ} 11.111$, Santa Rosa.

39 Mi Tierra, n. ${ }^{\circ} 121$, diciembre, 1980, Santa Rosa.

40 Véase Cantera (2017, pp. 254-274).

41 Entrevista a Adolfo Sánchez.
} 
la sembradora "mínima labranza". Estas herramientas eran recomendadas por el INTA y sus características divulgadas a partir de las circulares de extensión y otras publicaciones dirigidas a los productores de la región. Es importante entonces remarcar que, a partir del caso analizado, se pone en un primer plano el rol que tuvo la complementariedad entre los actores en cuestión al momento de realizar acciones que alcanzaron relevancia productiva en diferentes provincias de la Argentina. El proceso erosivo iniciado en los años treinta, cuyas consecuencias se estudiaron en las décadas siguientes, operó de manera determinante en la dinámica de la innovación agrícola en el período estudiado.

La relevancia que esta problemática tenía en las agendas oficiales, tanto del Cobierno nacional como del provincial, permitió que la actividad de Industrias Maracó en la producción de este tipo de artefactos tuviera continuidad entre las décadas del cincuenta y el setenta, situación que posibilitó que desde los años sesenta la apuesta conservacionista fuera su principal carta de presentación, como advertimos en la publicidad que citamos al comienzo de estas páginas. No es difícil, entonces, explicar que uno de los espacios con mayor demanda de estos implementos fuera la región afectada durante las décadas previas por el proceso erosivo. El rol de esta pequeña industria, en una provincia donde el sector secundario no tenía la importancia que alcanzó en otras durante el mismo período, se conjuga, así, con el de los técnicos del Estado, en un contexto de amplia circulación de conocimientos sobre la producción en regiones áridas y semiáridas. Estados Unidos, debido también al proceso erosivo desarrollado en sus grandes planicies durante los años treinta, se posicionó como una referencia en ese sentido. No obstante, como vimos, la incorporación de prácticas y herramientas generadas para otros espacios no fue un proceso mecánico; por el contrario, requirió diferentes ajustes y ensayos a la hora de su aplicación en los suelos argentinos.

\section{Bibliografía}

ALAPIN, H. (2008). Rastrojos y algo más. Historia de la siembra directa en Argentina. Buenos Aires: Editorial Teseo-UB.

BELINI, C. (2009). La industria peronista. Políticas públicas y cambio estructural, 19461955. Buenos Aires: Edhasa.

BELINI, C. (2017). Historia de la industria en la Argentina. De la Independencia a la crisis de 2001. Buenos Aires: Sudamericana.

BIJKER, W. (2013). La construcción social de la baquelita: hacia una teoría de la invención. En Thomas, H. y Buch, A. (coords.), Actos, actores y artefactos. Sociología de la tecnología (pp. 63-100). Bernal: Universidad Nacional de Quilmes.

CANTERA, S. (2017). Industria metalmecánica y desarrollo local: actores, políticas y entramado institucional en Ceneral Pico, La Pampa (1976-2001). Tesis doctoral, 
Doctorado en Ciencias Económicas, Universidad Nacional de La Matanza, Buenos Aires [inédita].

CUNFER, G. (2005). On the Great Plains: Agriculture and Environment. College Station: Texas A\&M University Press.

DI LISCIA, M.S. y MARTOCCI, F. (2012). De la abundancia a la desesperación: viajes y representaciones sobre los recursos naturales en el interior argentino (La Pampa, ca. 1880-1940). Revista Brasileira de História da Ciência, 5(1), pp. 11-27.

DJENDEREDJIAN, J.; BEARZOTTI, S. y MARTIRÉN, J.L. (2010). Historia del capitalismo agrario pampeano, tomo VI. Expansión agrícola y colonización en la segunda mitad del siglo XIX. Buenos Aires: Editorial Teseo-UB.

GIRBAL-BLACHA, N. (2003). Mitos, paradojas y realidades en la Argentina peronista (1946-1955). Una interpretación histórica de sus decisiones político-económicas. Bernal: Universidad Nacional de Quilmes.

HANSEN, Z. y LIBECAP, G. (2004). Small Farms, Externalities, and the Dust Bowl of the 1930s. Journal of Political Economy, 112(3), pp. 665-694.

HORNBECK, R. (2009). The Enduring Impact of the American Dust Bowl: Shortand Long-Run Adjustments to Environmental Catastrophe. National Bureau of Economic Research, Working Papern. ${ }^{\circ} 15605$, pp. 1-40.

HUICI, N. (1988). La industria de maquinaria agrícola en Argentina. En Barsky, O. et al., La agricultura pampeana. Transformaciones productivas y sociales (pp. 141-175). Buenos Aires: FCE, IICA, CISEA.

INTA (2009). 50 aniversario de la UEy DT Ceneral Pico "Agr. Héctor F. Peters". Desde siempre un compromiso con la innovación y el desarrollo. Anguil: Centro Regional La PampaSan Luis, EEA Anguil "Ing. Agr. Guillermo Covas", INTA.

LLUCH, A. (2017). Políticas públicas, planificación y promoción del desarrollo económico en la provincia de La Pampa (1955 ca. 1976). En Lluch, A. (ed.), Desarrollo, políticas públicas e instituciones. La experiencia de La Pampa en una visión de largo plazo (pp. 19-66). Santa Rosa: EdUNLPam.

LLUCH, A. y COMERCI, M.E. (2011). La economía de La Pampa: una perspectiva de largo plazo (1930-2001). En Lluch, A. y Di Liscia, M.S. (eds.) Historia de La Pampa II. Sociedad, Política y Economía de la crisis del treinta al inicio de un nuevo siglo (pp. 1556). Santa Rosa: EdUNLPam.

MARTOCCI, F. (2014). La producción agrícola en los márgenes: prácticas, saberes e innovaciones en el Territorio Nacional de La Pampa (1883-1940). Boletín del Instituto de Historia Argentina y Americana “Dr. Emilio Ravignani”, tercera serie, (41), segundo semestre, pp. 11-48.

MARTOCCI, F. (2018) ¿Cómo resolver los problemas del agro en el interior argentino? Las iniciativas estatales para la formación de técnicos y el desarrollo de investigaciones científicas en La Pampa (1952-1959). Apuntes. Revista de Ciencias Sociales, XLV (83), pp. 5-36. 
RAS, N. (1994). La innovación tecnológica agropecuaria. Aspectos metodológicos de la transferencia de tecnología. Buenos Aires: Academia Nacional de Agronomía

SCHUBERT, S.D.; SUAREZ, M.J.; PEGION, P.).; KOSTER, R. y BACMEISTER, J.T. (2004). On the Cause of the 1930s Dust Bowl. Science, 303, pp. 1855-1859.

SIMONASSI, S. (2013). El desarrollo industrial en debate: gobierno desarrollista y sector industrial en la provincia de Santa Fe, 1958-1962. En Rougier, M. (comp.), Estudios sobre la industria argentina, 2, (pp. 69-98). Buenos Aires: Lenguaje claro WORSTER, D. (1979).Dust Bowl: The Southern Plains in the 1930s. New York: Oxford University Press.

\section{Fuentes}

Agronales, serie: 1959, Estación Experimental Agropecuaria, Anguil, La Pampa.

Amit, I. (1965). Discurso pronunciado en Eduardo Castex por el señor gobernador de La Pampa con motivo de la Fiesta Provincial del Trigo. Santa Rosa: Talleres Gráficos de la Dirección de Imprenta y Boletín Oficial.

COLOMBATO, J. (1998). En tiempos del viento grande. Santa Rosa: Inédito.

COVAS, G. (1958). Festuca alta. Pasto perenne recomendable para establecimiento de pasturas permanentes en la región semiárida, Circular de extensión n.$^{\circ} 8$, diciembre. Anguil: Secretaría de Estado de Agricultura y Ganadería de la Nación, INTA, Estación Experimental Regional Agropecuaria.

COVAS, G. (1963). Dispositivos para mejorar la labor de las sembradoras, Circular de extensión n. ${ }^{\circ}$ 19, julio. Anguil: Secretaría de Estado de Agricultura y Ganadería de la Nación, INTA, Estación Experimental Regional Agropecuaria.

COVAS, G. (1969). Panizo azul. Un pasto perenne estival de gran productividad y rusticidad para la región semiárida pampeana, Circular de extensión n. ${ }^{\circ} 29$, mayo. Anguil: Secretaría de Estado de Agricultura y Ganadería de la Nación, INTA, Estación Experimental Regional Agropecuaria.

COVAS, G. y KNUDTSEN, O. (1958). El rastrón poceador. Una herramienta eficaz para prevenir la voladura de los campos, evitando la erosión, Circular de extensión n. ${ }^{\circ} 2$, junio. Anguil: Secretaría de Estado de Agricultura y Canadería de la Nación, INTA, Estación Experimental Regional Agropecuaria.

COVAS, G. y SARASOLA, J.A. (1966). Más informaciones sobre el rastrón poceador, Circular de extensión n. ${ }^{\circ}$ 25, septiembre. Anguil: Secretaría de Estado de Agricultura y Ganadería de la Nación, INTA, Estación Experimental Regional Agropecuaria.

DUVAL, M. (1940). Memoria presentada al Superior Gobierno de la Nación 1939-1940. Santa Rosa: Talleres Cráficos de la Gobernación de La Pampa.

DUVAL, M. (1941). Memoria presentada al Superior Cobierno de la Nación, Período: 19401941. Santa Rosa: Talleres Gráficos de la Gobernación de la Pampa.

Huallquitun, serie: 1970, Agencia de Extensión Rural, INTA, Ceneral Pico, La Pampa. 
IPUCHA Aguerre, ]. (1964). El Instituto de Suelos y Agrotecnia, pionero de la conservación en el país, en IDIA, n. ${ }^{0} 13$, INTA, pp. 5-10.

IPUCHA Aguerre, ]. (1966). América se moviliza para la conservación del suelo, en Ingeniería Agronómica. Revista del Centro Argentino de Ingenieros Agrónomos, n. ${ }^{\circ} 2$, tomo 24, abril-junio, pp. 13-14.

ITRIA, C.D. (1969). La alfalfa en la República Argentina. IDIA, n. ${ }^{\circ}$ 21, INTA, pp. 1-82.

KUGLER, W.F. (1964). Plan de extensión en conservación de suelos y establecimiento y manejo de pasturas para la región pampeana semiárida, en: IDIA, n. ${ }^{\circ} 13$, INTA, pp. 59-62.

La Arena, serie: 1977 y 1980, Santa Rosa, La Pampa.

La Reforma, serie: 1954, Ceneral Pico, Provincia Eva Perón.

Mi Tierra, serie: 1980, Santa Rosa, La Pampa.

Ministerio de Agricultura de la Nación (1940a). Memoria correspondiente al ejercicio de 1939, tomo I. Buenos Aires: Ministerio de Agricultura de la Nación.

Ministerio de Agricultura de la Nación (1940b). Memoria correspondiente al ejercicio de 1939, tomo II. Buenos Aires: Ministerio de Agricultura de la Nación.

Ministerio de Agricultura de la Nación (1941). Memoria correspondiente al ejercicio de 1940, tomo I. Buenos Aires: Ministerio de Agricultura de la Nación.

MOLFINO, R.H.; Prego, A.; Offermann, A.M.; Zaffanella, M. y Reichart, M.A. (1952) . La fertilidad del suelo pampeano (Simposio). Buenos Aires: Publicaciones del Instituto de Suelos y Agrotecnia.

PÁEZ, J. (1948). Por La Pampa y sus hombres (dos años de gobierno del Territorio). Santa Rosa: Gobernación de La Pampa.

PÉREZ VIRASORO, E. (1938). Memoria presentada al Superior Gobierno de La Naciónaños 1936-1937. Santa Rosa: Talleres Gráficos de la Cobernación de La Pampa.

POSE RODRÍCUEZ, G. (1959). Almacenamiento, conservación y uso de la humedad del suelo. Prácticas sencillas que contribuyen a evitar los efectos de los períodos de sequía en la región semiárida, Circular de extensión n. ${ }^{0}$ 12, abril. Anguil: Secretaría de Estado de Agricultura y Ganadería de la Nación, INTA, Estación Experimental Regional Agropecuaria.

PREGO, A., TALLARICO, L.A., BELLÓN, C.A. y CALCAGNO, J. (1955). Relevamiento detallado del área de la Estación Experimental de Anguil (Pcia. de La Pampa). Buenos Aires: Ministerio de Agriculturay Ganadería, Dirección General de Investigaciones Agrícolas, Instituto de Suelos y Agrotecnia.

PREGO, A. (1955). Almacenamiento y conservación del agua en el suelo. Agro Pampeano, (2), marzo-abril, p. 10.

PREGO, A. (1967). El problema nacional de la aridez y su conocimiento por los argentinos. IDIA, n. ${ }^{\circ} 19$, INTA, pp. 6-8.

SILBERMAN, R. (1955). Modernos métodos de lucha contra la tucura en el Establecimiento 'San Remigio' del Sr. Juan Harriet. Agro Pampeano, (2), marzoabril, pp. 9-10. 